\title{
Community Networks and the Nature of Emergence in Civil Society
}

\author{
Jenny Onyx and Melissa Edwards ${ }^{1}$ \\ University of Technology, Sydney
}

\begin{abstract}
Our research challenges the limitations of extant knowledge of social formation by its focus on the ordinary, everyday lived reality of maintaining community and on identifying its operations from the internal perspective of civil society. We aim to explore the actual mobilising processes and structures that underpin the formation of social capital in the community. We examine how networks emerge and operate.
\end{abstract}

\section{Introduction}

Within this paper we seek to examine how social capital may enable locally sustainable development within a local community context. Theoretically we situate this analysis in broader discussions relating to the role and contribution of civil society. We seek to examine how such arguments that advocate a functioning role of civil society may be enabled through the emergence and functioning of locally based community networks. Rather than seeking normative perspectives we seek to understand how networks within communities may selfactivate in circumstances of market or state failure to sustain their livelihoods.

Civil society functions, in part through its organisations, but also through the interconnected collective action within communities. Various conceptual frames have been generated to analyse civil society (Seligman, 1992; Foley and Edwards, 1996). Foley and Edwards (1996) establish a dichotomous view, "Civil Society I" following de Tocqueville which empahises associational life and "Civil Society II" with an emphasis upon action-oriented forms of voluntary participation which may be in conflict with the state or market. In our analysis we take the view that aspects of both perspectives may be useful in understanding how social capital is generated to sustain locally based communities.

We argue that social capital is an essential ingredient in enabling that community cohesion and well-being, however our conceptual perspective is informed beyond the normative

\footnotetext{
${ }^{1}$ Two of the case studies reported in this article, Anapia in Peru and Lovik in Sweden, were completed with Rosemary Leonard of University of Western Sydney.
} 
definition of social capital as derived from the studies of Putnam (2000). As civil society perspectives are contested so too the conception, measurement and impact of social capital within studies broadly situated within civil society are contested. We take the view that in understanding the role of social capital in a functioning civil society within a community context it is necessary to combine these perspectives.

Social capital, like most other social constructs, is subject to disputed definition. Social capital is defined as "those features of social organization, such as trust, norms and networks that can improve the efficiency of society by facilitating coordinated actions” (Putnam 1993). Bourdieu (1985, p.248) defined the concept as "the aggregate of the actual or potential resources which are linked to possession of a durable network of more or less institutionalized relationships of mutual acquaintance or recognition”. For Bourdieu, social capital was a core strategy in preserving and transmitting the cultural capital of the elite. Because all forms of capital can be converted into other (primarily economic) capital, social capital was one way of preserving class advantage. However other theorists including Coleman (2000) and Putnam (1993), view social capital as a resource (often the primary resource) that is open to all groups and communities. Schuller (2001) argues that it is not that all capitals are ultimately reducible to economic capital, but that they interact in complex ways, and indeed the value of social capital may well depend on its linkage to other capitals.

Prior studies of social capital seeking to quantify the effects of social capital have found that regions and groups measuring high social capital also have a variety of positive outcomes, beyond economic advantage, such as improved health and well-being, reduced levels of crime and better educational outcomes (Putnam 2000; Halpern 2005).We know that communities have the capacity to mobilize, especially under conditions of extreme emergencies such as floods or bush fires. However, we know little about how this occurs.

A relevant line of inquiry is the link between social capital and sustainable development (Dale \& Onyx 2005). An important ingredient in sustainable development is local capacity for action. Rogers and Ryan (2001) argue that sustainable communities “empower people with shared responsibility, equal opportunity and access to expertise and knowledge, with the capacity to affect decisions which affect them” (2001, p282). This includes the development of locally specific information and indicators of progress. However, while we know that 
social capital as variously measured is related to development, we do not understand the mechanisms by which this may occur or be prevented (Dale \& Onyx 2005).

Social capital is often taken as a kind of black box. Its existence and effects may be measured, but the mechanisms by which it operates are left unexamined. The definition of social capital identifies some of its component parts, such as "trust, norms, networks" (Putnam 1993) and "social agency" (Onyx \& Bullen 2000). But there is little understanding of how social capital is formed and mobilized. We need to understand the emergent formation of social capital, and hence of community capacity. What are the mechanisms by which information is shared, decisions are made, and community action is mobilized? Similarly, after considering various social capital perspectives, Edwards and Foley (1998, p. 135) conclude that a "social relational” approach to social capital analysis "focusing on social networks and organisation” would be a preferential conceptualization. Networks appear to be the basic ingredient of all community action. But what kind of networks, how formalized, for what purpose, and what specific impact are all questions about which there is little understanding.

Most of the extant literature on networks is oriented from the perspective of business or government. There is a vast literature on organisational theory, including that of interorganizational collaborations (Eden \& Huxham 2001; Hardy, Phillips \& Lawrence 2003) and entrepreneurship, all designed to understand how best to organize and mobilize resources for business. The dominant issue is one of control. Government policy is also interested in how to support and mobilize community capacity to carry out government policy; again the issue is how to manage and control community action, usually through some sort of legislative mandate and funding accountability. In Australia, for example all levels of government have specific policies and departments dedicated to the management of community and society. Predominantly, the focus is on mobilizing and establishing management control over the network as a whole.

Only in social movement theory, is there a real interest in how the community mobilizes itself, which is mobilization from the perspective of civil society. Social-movement theories analyse "organisations, resources, structural preconditions, networks and rational choice” (Johnston \& Klandermas 1995), and more recently, identity, culture, norms and transnational advocacy (Melucci 1995; Khagram, Riker \& Sikkink 2002). The vast array of social 
movement literature concerned with understanding how social movements operate tend to focus upon: when social movements emerge, the roles they play in social life, the types of impact they have (outcomes) and the conditions under which they can be effective (Khagram, Riker \& Sikkink 2002). Diverse perspectives offer different answers to each of these dimensions. Theorists have attempted to find conceptual linkages to fortify the field (Diani 1992) to provide space for interpretations and perspectives to reflect the dynamic and global nature of social change (Langman \& Morris 2002; Bosco 2001), drawing across research traditions employing 'relational' techniques focusing upon network creation. In fact New Social Movement theorists specifically focus on the network as the unit of analysis (Scott 1990; Diani 1992). Largely these theories seek to uncover the mechanisms of large scale social movements and their co-ordination, which is of the extraordinary.

But what of the ordinary, everyday lived reality of maintaining community? How does that work from the internal perspective of civil society? What are the actual processes and structures that underpin social capital, community capacity? Edwards and Foley (1998) determine such a focus on network analyses as an impending area for empirical investigation.

\section{Understanding the mechanisms for community mobilization through complexity theory}

To better understand the mechanisms influencing people’s shared capacity for action, we draw on recent developments in complexity theory. Chia (1999) argues that we need a "rhizomic model" of organizations, in which change and transformation is the norm. We need to shift our thinking from assumptions of institutionalized structure and stability to one of flux, in which "all things flow" in a continuous process of becoming, in which what is now contains the traces of what was, and the seeds of what is yet to be, that is the principle of immanence. Networks are malleable, interconnected and framed within the context of their emergence.

Complexity theory offers an insight into the fundamental issue of emergence (Chiles et al. 2004). It offers an explanation for "how system-level order spontaneously arises from the action and repeated interaction of lower level system components without intervention by a central controller” (Chiles et al. 2004, p.501). This theoretical approach can be applied to emergent self-organizing networks within civil society. How do community networks develop and how does this occur without intervention though a deliberate community 
capacity development strategy, agency or preexisting organisation? Furthermore, this may provide some insight into social capital formation through social networks.

Complexity theory is concerned with complex adaptive systems (Uhl-Bien et al. 2007). A complex system is not merely complicated; it is complex because "the system as a whole cannot be fully understood simply by analyzing its components” (Uhl-Bien et al. 2007, p.302). In the case of civil society, we are dealing with multiple and overlapping complex systems which may be partly, but never totally, bounded by a geographical area such as a community. The systems are not only overlapping, but open, thus adding to the levels of complexity. Nonetheless they have meaning to their participants, and they are capable of generating remarkable outcomes.

Complexity theory suggests a number of crucial dynamics that may explain the process of the self-organizing emergence of networks (Cilliers 2005; Byrne 1998), many of which are summarised in the table 1 (below).

Table 1: General Characteristics of Complex 'Systems'

1. Complex systems consist of a large number of elements which in themselves can be simple

2. The elements interact dynamically by exchanging energy or information. These interactions are rich. Even if specific elements only interact with a few others, the effects of these interactions are propagated throughout the system.

3. The interactions are nonlinear.

4. There are many direct and indirect feedback loops.

5. Complex systems are open systems - they exchange energy or information with their environment and operate at conditions far from equilibrium.

6. Complex systems have memory, not located at a specific place, but distributed throughout the system. Any complex system thus has a history and the history is of cardinal importance to the behaviour of the system.

7. The behaviour of the system is determined by the nature of the interactions, not by what is contained within the components. Since the interactions are rich, dynamic, fed back, and above all, nonlinear, the behaviour of the system as a whole cannot be predicted from an inspection of its components. The notion of 'emergence' is used to describe this aspect. The presence of emergent properties does not provide an argument against causality, only against purely deterministic forms of prediction.

8. Complex systems are adaptive. They can (re)organise their internal structure without the intervention of an external agent.

These principles may be used as a means of reconceptualising how social networks function. First, they emerge out of states of disequilibrium, or a tension between disequilibrium and equilibrium in the wider context (Plowman et al. 2007). Multiple lines of positive and negative feedback loops (Cilliers 2005, p.8) are crucial in establishing new modes of operating. That is, through action and interaction people start to develop a collective sense of 
how they can cooperate, but also share experiences where organising was not functional and learn to avoid repetition of such actions and interactions. Stability within the embryonic network is dependent on the development of 'deep structures' involving shared intrinsic values, and operating principles of the participants. These are attained through the positive and negative feedback loops and held within the dissipated, 'collective memory' (Cilliers, 1998) of the emergent network.

Complexity theory gives leadership a central place, but where adaptive leadership is dynamic and "is the product of interaction, tension, and exchange rules governing changes in perceptions and understanding” (Lichtenstein et al. 2006). This approach to leadership is in marked contrast to the classical organizational model of leadership which emphasizes hierarchy and control (Avery 2004; Chiles et al. 2004). Such views of leadership rest on the assumption "of organizations as equilibrium seeking systems whose futures are knowable and arrived at by leaders who plan interventions and control behaviors” (Plowman et al. 2007, p.341). By contrast, within complexity theory, leadership should not be viewed as individuals operating in isolation as they influence their followers, or in terms of individual traits. Leadership is seen as an emergent phenomenon that arises from interactions and events (Lichtenstein et al. 2006). A similar approach (Surie \& Hazy 2006) argues that, with respect to innovation, generative leaders create conditions that nurture it rather than direct or control it. In a similar manner, some forms of collective entrepreneurship, involve emergent and/ or dispersed leadership in a social context. Johannisson and Olaison (2007) argue for a concept of "enactive entrepreneurship" associated with social creativity, and made particularly visible in the case of a natural disaster or emergency situation facing a community.

As a heuristic device, we use some of these key principles of complexity to analyse the emergence and functioning of social networks within three community case studies where participants were encountering prospects of decline; one drawn from Australia, one from Peru, and one from Sweden.

\section{The Case Studies}

Each of the case studies from Australia, Sweden, and South America were selected because they had demonstrated community development. The choice of case studies was determined by colleagues with a detailed knowledge of each location. The main criteria were that there is a definable small community ( $<5000$ people) that had a relevant organisation that was willing 
to auspice the research and had demonstrated community development capacity. The latter criterion required a clear project for the social or economic benefit of the towns.

Each case involved observation of the community, interviews with key informants, and a variety of secondary source data. A thick description was developed for each. In each case informants (between 5 and 15) were sought from across the community who are involved in the community development strategies, and possibly some who are critical of the developments. The informants represented a variety of social roles and a cross-section of gender, age and education. Recruitment was by invitation from the auspicing organization, with follow-up interviews using a snow ball sampling method. Participants were interviewed for approximately one hour roughly following an open-ended interview schedule with scope for the informant to introduce new material. The interview method was selected to allow maximum flexibility and input from the participants. In South America, an interpreter was provided by the host research institute. Interviews were electronically recorded and stored on the computer of the chief investigators (in Sweden only basic summary data was so recorded).

In addition to the interview transcripts, the analysis depends heavily on field notes taken by the authors from observation of the actual field sites, visits to key community houses, organizations and events, and participation in community activities. In addition, census data, reports, web page information and other available information about the communities and their organizations was collected to supplement the interviews.

A thematic analysis identified the major issues for each case, based initially on the broad interview questions. However there was a recursive trawling of the data in search of emergent themes not previously identified, thus roughly approximating a grounded theory approach. It is from this analysis that insights concerning emergence of community formations.

\section{Results}

In this section we present a brief sketch of the three communities.

\section{Maleny, Australia}

Maleny is a small town in the hinterland of Southeast Queensland. A major disequilibrium occurred when the struggling dairy farming area experienced an influx in the 1970s of new 
residents who held a commitment to an environmentally sustainable lifestyle. The new residents identified the need for more services and four of these new residents, led by one woman in particular held meetings of residents to explore the possibility for community development. The main leader was one of the early settlers, living in an organic farming housing settlement on the outskirts of Maleny. The idea emerged of developing co-operative organisations to serve the community, starting with a credit union and an organic farm produce outlet. The active initiative of the group was particularly evident in their study tours of other centres and in obtaining an expert to assist in setting up the first co-operatives. Since these were moderately successful a positive feedback loop was formed and other cooperatives followed the first, including a community café, and various commercial enterprises. Some local residents, especially the dairy farmers, were initially resistant to the new developments, but increasingly were included in community plans and a local newspaper was formed to keep the wider community informed. The main leader appeared to work with great skill and dedication, involving many other people in the gradual evolution of the new town. Although she was central to the formation of each new venture, she seldom took a management position.

Maleny is now a prosperous community with a population of approximately 4,000 and has a large number of community organisations spanning diverse functions. According to the database created through the local Maleny Working Together (MWT) project involving a survey of 411 households as part of a community audit, (and initiated by the same female leader) there are 136 community groups within the Maleny local area (MWT, 2003, p. 14). Many people (40\%) volunteer their time in some capacity and there are strong interconnections between community organisations as over $90 \%$ of local community groups dialogue with others locally (MWT, 2003, p. 14) indicating a tightly interwoven collection of community organisations. These interconnections are partly due to individuals belonging to many different organisations simultaneously. Informally this provides a flow of information between different organisations and sharing of resources. Eighty-eight per cent of the sample felt that it was easy to be involved in the community.

As Maleny reached a new equilibrium there was evidence of the formation of deep structures based on shared values. An important shared value is to create as near as possible selfsufficient sustainable communities based upon local cooperation and place bound networks. A related value was its commitment to the environment and they received an award for 
Environmental Citizen of the Year. The openness of the local community was another related value that makes the town special. According to one interviewee:

It's an energy thing you just seem to tune in to. It's vibrant, it's interesting, it's very diverse and to a large extent it's the people. It is very accepting. It doesn't matter what your background is, age, sexual preference whatever, it makes no difference (Female informant).

As evidence of the strength of the shared values, survey data revealed that Maleny recorded the highest social capital factor across all those communities surveyed in Australia (Edwards \& Onyx 2007). Maleny scores were high across all the social capital factors including community connections, trust, neighborhood connections, tolerance of diversity and social agency $^{2}$.

The strength of these deep structures was tested by a recent disequilibrium caused by the approval by the local council of a large new supermarket for a national retailer on the bank of a river with endangered platypus. The Obi Obi campaign signalled a general community resistance to the development involving most groups in town, including the cooperative movement and local business owners, as well as environmental and social groups. Although the complex was built, local residents continue to boycott the stores. At the time of the Obi Obi campaign, the woman who had been the early leader was active, but no longer central to the organisational resistance.

\section{Anapia, Peru}

Anapia, population 2000 is the most remote of the islands in Lake Titicaca of Andean Peru. Reaching Anapia requires a 2.5 hour car trip from Puno, the regional capital, followed by a 1.5 hour boat trip. The people identify as Aymaran and the main economic activities are agriculture and fishing. It is basically a subsistence economy, with little money exchange. Most people own land and/or a fishing boat. However there are a few landless families who work on other people's land in exchange for a share of the produce.

\footnotetext{
${ }^{2}$ Further details of this study can be found in Onyx and Bullen (2003) and Onyx et al (2009). Seven urban and rural communities have been surveyed and contrasted using a social capital survey tool designed by Onyx and Bullen (2003). Analysis across factors seeks to determine variation between communities. Maleny scores were the higher overall, but also the highest across all factors, being a very strong indicator of the existence of social capital in the community.
} 
A major disequilibrium occurred in the mid 1990s, when a local entrepreneur and citizen, who had completed some tertiary education in Puno, explored the possibility of developing eco-tourism on the island as a means of economic development, but without losing the cultural heritage and ways of life as had happened in other islands where tourism had already been developed.

Anapia has a unique process of decision making. On the first Saturday of each month, the entire community meets in the central plaza. Under the management of the Mayor, issues of community wide concern are discussed. It is through this process that the social entrepreneur was able to present his case for the tourist project, to have the project thoroughly discussed and debated. There was some conflict as some community members were concerned that outsiders would bring new diseases and that it would change their way of life. Others feared that they could not provide adequate service to these strangers. They reported that they had to overcome fear and shame in interacting with the tourists, and they are still very anxious about their ability to please. It took two years of intense discussion within the community before they were ready to undertake the project. Although all the dissenters were not convinced, an association called Adeturs was formed.

Unfortunately there was no immediate positive feedback as only a few tourists arrived the first season and none the next. The entrepreneur persisted, however, and sought a partnership with a travel agent, in which the community would maintain the initiative and control. All Ways Travel agreed to promote the Island as an eco-tourist destination, and to assist the islanders to develop a quality product. Communication with Puno was difficult (and still is) with unreliable telephone service. The leader himself went to Puno to find the tourists and bring them back to Anapia.

With several thousand years of shared culture and lifestyle there are very deep structures and shared values and these principals were used to organise the new venture. The organisational system they chose was consistent with the traditional Iynu system of organization in agriculture by which work is collectively organised but each family has their individual plot from which they obtain the produce. Translating this into tourism meant that in strict rotation, each family hosts tourists and benefits from the financial return. A strict limit was applied to maximum tourists to be hosted by each family (one couple per week). Other families were involved in related activities such as transport and meal preparation. This system ensured a 
more equitable distribution of income, where no one person could get rich at the expense of others.

All those involved in one of the four tourist activities are members of the relevant subcommittee (maximum of two activities per family) and all decisions are made by consensus. Each committee, as well as Adeturs itself, has a president elected every two years, as well as a treasurer. Adeturs provides overall co-ordination of the four committees. Within Anapian society and Adeturs, the women play a major role. Although most of the senior offices are held by men, women take an active role in public meetings and on committees and in developing their homes for tourists. All families involved in Adeturs are required to work collectively to improve the village, keep streets clean of rubbish, etc.

The new venture required creative thinking, so as members of Adeturs realised they needed to increase their skills and knowledge they also created the solutions. Some training and advice was provided by All Ways Travel but they needed to travel beyond the island. Groups of women travelled, sometimes for the first time in their lives, to gains the skills they needed and to promote their program. However, the residents are also gradually recognizing the value of their traditional knowledge, taking pride in it and sharing it with the tourists. The program is also providing fertile ground for other ventures. One woman gave a presentation on their program in a community development competition in the national capital. With the prize money they built a community centre with a small library. A volunteer tourist program helped paint the school.

The entrepreneurial leader who started the tourist project, and was president of Adeturs for many years, is now Mayor of the Municipality and a new leader has been elected for Adeturs. The community is confident that they can maintain control of the development process, and are ready to expand.

\section{Lovik, in North west Sweden}

Lovik is a tiny village of less than 100 people, located in the remote region of northwest Sweden. Many towns had been left to die following the mechanization of the timber industry and the loss of subsidized support for farming. However despite this severe crisis, the village was determined to revitalize itself. This process began in 1989 with a public meeting called in neighbouring Hoting. One woman went “just for entertainment” but as a workshop exercise 
they were asked to write their thoughts on the future. Her vision and that of another woman were of Lovik as a well-developed centre. A female economist challenged her to "go away and do it” She couldn't sleep and was worried that the men would laugh at her but nonetheless she called a public meeting at Lovik and much to her surprise 25 of the residents came. Some men were sceptical but one older man was encouraging. The Community Development Advisor (CDA) attended and gave good examples of what had been done elsewhere. So they agreed to a second meeting at which they formed a voluntary association "Ideal Village of Lovik and surrounds". Its mission was the economic, social and cultural development of the area. The first activity was a cabaret to raise money using local musical talent. With the profits they repaired the community hall and put on a series of social fundraising events for visitors especially in the hunting season (ongoing). They created an annual accordion festival with up to 1000 visitors, many from other countries in which the local residents provide accommodation in their own homes.

From 1989 the old people talked about the need for a retirement centre in the village and asked the organisation to speak to the Municipality. They were helped by the Community Development Adviser (CDA) who was employed by the Municipality but funded by the State. There were many obstacles: first the Municipality said the village was too small, second, they knew nothing about setting up a cooperative. Little happened for a year. Then four women (teacher, teacher's aide, post office worker, and bank worker) and the CDA formed the task force. They worked on a tight schedule and achieved their goal in 17 months (including the building of the home). They experienced jealousy and resistance from the Municipality and the CDA resigned as a result. The prevailing attitude of Municipality was "Don't think you are better than anyone else.” Our informant said that it was because she was voluntary that she was able to speak out. They did however get good support at the National level from one Minister in particular, a woman and obtained a low interest loan.

The eldercare cooperative had 18 members, those who lived there, those who worked there and those from the village. The membership required 1000 Kronor (\$200) and 40 hours of work per year. Husbands of the four women mowed the grass, delivered material and food, and did maintenance. There were six apartments each with en-suite and kitchenette. It had an attractive modern design with ecological awareness (eg heating from under the earth). The service cost less than similar Municipal services because of all the voluntary labour. Voluntary labour was seen as part of developing community. Day to day decisions were 
made around the kitchen table (eg to keep hens). A recreational account was built up from miscellaneous income. The Municipality funded 3.5 personal care positions (shared by 5 women) so it brought employment to the village. A qualified nurse came once a fortnight. At night there was an emergency call button and a night patrol. There was a room for relatives to stay. Other villages subsequently developed similar eldercare cooperatives. The Lovik eldercare centre became a model for Sweden and received thousands of visitors from all over Sweden and other countries.

The latest project was for the five children in the village. At the time of the fieldwork they were building a playground next to the eldercare accommodation. The association was planning a "revivalist" meeting of ex-residents with the Minister of Agriculture in Stockholm. The aim was to encourage people to return to the village, particularly those nearing retirement.

\section{Discussion}

Each of these three rural case studies from different parts of the world has unique conditions and problems but they were selected because they have demonstrated a capacity to develop or to re-invent their town in the experience of market or state failure. In all cases some kind of project was developed and managed by the community. That is, each clearly demonstrates the rhizomic phenomena identified by Chia (1999), in which change and transformation is the norm. We did not find institutionalized structure and stability but rather an ongoing situation of flux, in which "all things flow" in a continuous process of becoming. Each case also demonstrates the fundamental issue of emergence (Chiles et al. 2004); that is, system-level order spontaneously arose from the action and repeated interaction of lower level system components and were not directed by a higher authority or a central controller” (Chiles et al. 2004).

Network emergence through the complexity lens.

Complexity theory concepts are also useful in describing the sometimes difficult and haphazard path to developing a new project. Each case evidenced disequilibrium, sometimes in terms of a crisis as in Lovik, sometimes in terms of changing economic conditions and the desire to create alternative sources of income as in Anapia. Conflict was evident and sometimes encouraged as new ideas were introduced and debated, and sometimes resisted. In all cases there were a series of meetings and a variety of discussions leading to the creation of 
new organisations, and a search for the necessary resources or knowledge to achieve a desired outcome. In each case there were serious obstacles to the development of the project. These included obstacles of resistance from within the community (Anapia for example), obstacles imposed from outside (as in the case of Lovik in particular) and the difficulty of obtaining the necessary human and financial capital. In most cases these obstacles created an initial period of inaction or discouragement. It took a year or more before there were clear signs of successful achievement. During this interim period it was usually the leader who maintained optimism and persisted in the search for solutions to the obstacles. As Johanisson and Olaison note (2007, p.58), these entrepreneurial practices are "driven by passion and joy”. It was probably this perseverance that earned her or him the lasting respect and trust of the community. From this we might deduce that the early stages of emergence are likely to be marked by conflict, not only between the member agents and some wider social or political issue or event, but also between the member agents themselves. The state of disequilibrium may be deliberately created or amplified; it may only be through such turmoil that a new, creative milieu can emerge, one which may generate innovative solutions to perceived problems.

In each of the communities reported here, the wider community networks mobilized themselves in a self governing and self regulating manner out of this milieu. In each case this process within the project appeared to mirror established decision making processes within the community at large. That is, there was, in each case, a culture of grass roots participation and decision making for all issues affecting the community at large. Anapia was the strongest example of this. Action occurred at several quite different points within the community, with many people taking some initiative at different times. Some of these actions lead nowhere, while other actions coalesced into a larger community campaign, as in Maleny.

What is also evident in each community was a deeper set of shared values, and a common commitment to sustainable development. These shared values highlighted the deeper levels of trust within the community, and strong bonding social capital. These norms did not override or eliminate conflict, but on the contrary made it possible for differences to be openly debated and compromises negotiated. Within the specific community projects, deeper structures of shared objectives emerged. Much of the early work of the project required extensive negotiations with a variety of key stakeholders both inside and outside the community. It was out of this negotiated consensus of often quite different positions and interests that the project 
was able to proceed. Hahn et al. (2006) also refer to the importance of resolving tradeoffs in creating a collective vision. In every case the project was then supported by a management committee with representation across the community, and with decision making responsibility.

In relation to the process of emergence then, the initial state of disequilibrium draws agents together. These agents may be individuals, or organizations or both. These agents interact, discuss, and explore options for action. Many consequent actions are small and localized, involving the active initiative of concerned agents. Some of these actions will lead nowhere, but others appear promising, and are communicated to others through positive feedback loops in the embryonic network, which at this stage is little more than a fertile milieu for action. Others hear about the actions and discussions, through word of mouth and/or electronic technologies, and/or published papers and media reports. Someone, usually a group, calls a meeting, and a network emerges as various agents share information and agree to further action. At some stage it is essential that some actions lead to some sort of positive outcome, perhaps partial and temporary, but enough to motivate others. Such results must be communicated to others in the network.

The discussion and forms of actions are volatile and full of uncertainty and potential conflict. However, while disequilibrium may be welcomed and further encouraged, there are also counter forces towards some sort of new equilibrium. These will be articulated in terms of a common set of principles or objectives signed off by all participating agents. Thus creative turbulence is contained within an agreed broad set of objectives that are shared.

\section{Enabling leadership guides emergence.}

Despite vast geographical and social differences there were also some important similarities in the nature of the leadership. In each case the identified leader or leadership group were strongly embedded within the formal and informal networks of the community. In most cases they took a strong initiating role in establishing the project. But while they may be the chair of the committee or co-operative that first established the project, they were not at that time in any other position of formal authority. Some, such as the leader in Anapia subsequently was elected as Mayor, but he obtained that position after having demonstrated his capacity in the earlier mobilization of the community project. In the other two cases, the mobilizing leader was one of a small group of active women who gave her the support she needed, and 
shared some of the leadership responsibilities. The leader was regarded always as "one of the people”, not an outsider. Although she or he may have had slightly better qualifications or status, the difference was not marked. Above all, they were trusted by the community, as a person of integrity who held the public interest foremost

In all cases the leaders appreciated that they were working with open systems and that they needed to engage with other places and structures. So they developed good links outside the village. This was especially important where most links were bonding links within the village and few people ventured outside, and where there was a culture of self-sufficiency. The leader may have had some bridging links to begin with, but in each case, they formed new ones in the course of the project, in order to fill identified gaps in knowledge, skills and material resources. For example, the leader in Maleny began the co-operative movement through an initial study tour, and then invited external experts to come and assist. Similarly the leader of Anapia sought out a tourist operator as commercial partner. The leader in Lovic formed an ongoing alliance with the CDA and later links to the national level. All these links were essential in the successful completion of the project. In a sense, the leader was able to fill the "structural holes" between the community and outside networks (Burt 1998). However they used these connections for public and not private gain. While it may be expected that the state, through the local government may be crucial in resourcing new developments, this was not the case in these three case studies. When local government was hostile as in Maleny and Lovik or indifferent as in Anapia, alternative paths to bridging were found through NGOs or other levels of government.

The leaders have a broad vision for what is possible in the future for the community. They are able to articulate this vision, and identify a path to achieve it. They are able to inspire others to follow that vision. That is, it is not simply a dream but one that can be actualized. This is the essence of visionary or transformational leadership (Avery 2004). It did not necessarily include a vision of future economic expansion. In all cases, the shared vision was one of ecological and social sustainability rather than economic expansion. This raises the question of what is meant by the distinction between "getting by" as opposed to "getting ahead" in Woolcock and Narayan's terms (2000). While all communities were concerned to maintain an adequate livelihood, this was only one consideration within a desire for a balanced development, one that put social and environmental issues in the forefront. However in Anapia, and Maleny, the vision did include the potential for both improved well being and an 
expanded economic base, albeit one firmly located within the ecological and cultural values of the community.

In the three cases, power belongs to the group rather than the leader. Change may be slower than the leader wished as in Anapia, by the need for extensive consultation and wider participation and acceptance of new practices. But this approach was highly successful in leading complex change in a dynamic environment. All the leaders engaged in bridging to obtain the necessary resources and expertise, thus they could be seen as social entrepreneurs. The theme that does not appear in any theory of leadership except complexity theory is that the leaders were embedded in their communities, and leadership action was emergent from the interaction of agents at that grass-roots level (Chiles et al. 2004; Lichtenstein et al. 2008). Indeed most theories emphasise the social distance between the leader and followers. However it is the embeddedness in the community and shared decision-making that help maintain social capital during the community development process.

\section{Conclusions}

The three cases reported here illustrate the complex process of emergence of new social formations within the local community. Other cases could have been chosen to demonstrate much the same phenomena. The capacity to develop new community projects depended on existing bonding social capital, with common values, existing strong multiplex networks, and good levels of trust. However the process of development also generated new forms of bonding and bridging social capital. In all cases, the project began with very little in the way of financial resources. However, good facilitative leadership created access to the necessary skills, knowledge and financial resources needed to complete the project. Above all, networks built trust, shared knowledge and made collective decisions that involved many community members, and in each case lead to the creation of one or more community organisations to manage the project(s).

None of this could have been predicted beforehand. As suggested by complexity theory, new, community wide social formations arose from the actions and repeated interaction of lower level components, that is, individuals and groups working within the community, but without the intervention of a centralized controller. There was no bureaucracy, no intervention by state or corporate power. The new forms were controlled by the grassroots community members, often in a dynamic process of creative learning, trial and error, mutual support and 
debate. Cooperative action produced positive feedback loops which enabled further learning and the courage to attempt more ambitious action. We have demonstrated that sustainable community development is a complex, emergent process enabled through the proactive selfformation of locally socially innovative solutions.

Within the context of civil society, we see coalescing relationships, between individuals who may be operating as individuals or as members of organizations. This coalescing of relationships creates a fertile milieu out of which may emerge new ideas, formations, intentions for collaborative action. Associations are significant, but also collective agency which may at times be antagonistic, but at others cooperative with the state is equally apparent. According to the dichotomy presented by Edwards and Foley (1998) we find that in the case of the community networks presented in these cases the analogies of civil society are not mutually exclusive, but may even be complementary. Perhaps this is due to the community context whereby there was an emergency or perceived crisis that required action for survival that triggers both the rapid formation of a new organizational form and collective action. This may be a useful avenue of future study regarding concepts of civil society.

We argue that the vast majority of civil society networks are formed from below, emergent from the dynamic and creative turmoil which is driven by social disequilibrium and the search for new responses to current issues and problems. Not all networks will become fully fledged and recognized forms. All such emergent networks will go through a period of formation, much of which will be invisible to the outsider, and lack any coherent shape. Other embryonic networks may remain as informal friendship networks or loose connections between residents of a given area. Such loose networks may remain dormant for most of the time, but have the potential to be activated into more formal networks in the event of an emergency, such as bush fire, or need for political action in defense of a threatened amenity. If and when that happens, they may evolve in much the same way as identified here.

\section{References}

Avery, G. 2004, Understanding Leadership: Paradigms and Cases, London, Sage Publications. 
Baker, E., Kan, M., Teo, S. \& Onyx, J. 2009, 'Managing dualities in a collaborative nonprofit network’, Third Sector Review, vol.15, no.1, pp.101-114.

Bosco, F. J. 2001, 'Place, space, networks, and the sustainability of collective action: the Madres de Plaza de Mayo’, Global Networks: A Journal of Transnational Affairs, vol.1, no.4, pp.307-329.

Bourdieu, P. 1985, 'The social space and the genesis of groups', Social Science Information, vol.24, no. 2, pp. 195-220.

Byrne, D.S. 1998, Complexity Theory and the Social Sciences; an Introduction, Routledge, London.

Chia, R. 1999, 'A rhizomic model of organizational change and transformation: Perspective from a metaphysics of change’ British Journal of Management, vol.10, pp.209-227.

Chiles,T. H., Meyer, A.D. \& Hench, T.J. 2004, 'Organizational Emergence: The origin and transformation of Branson, Missouri’s musical theaters’, Organization Science, vol.15, no.5, pp.499-519.

Cilliers, P. 1998, Complexity, Routledge, London.

Cilliers, P. 2005, 'Knowing Complex Systems', in K.A. Richardson (Ed), Managing Organisational Complexity: Philosophy, Theory, Application, IAP, Connecticut: pp.719.

Coleman, J.S. 2000, 'Social capital in the creation of human capital', in P. Dasgupta \& I. Serageldin (eds) Social Capital : A multifaceted perspective, The World Bank, Washington DC.

Dale, A. \& Onyx, J (Eds) 2005, A Dynamic Balance: Social Capital and Sustainable Community Development, University of British Columbia Press, Vancouver .

Diani, M. 1992, 'The Concept of Social Movements', The Sociological Review, vol. 40 no.1, pp.1-25.

Eden, C., \& Huxham, C. 2001, 'The negotiation of purpose in multi-organizational collaborative groups', Journal of Management Studies, vol.38, no.3, pp. 374-391.

Edwards, B. \& Foley, M.W. 1998, 'Civil Society and Social Capital Beyond Putnam', The American Behavioural Scientist, vol.42, no.1, pp.124-139.

Foley, M.W. \& Edwards, B. 1996, 'The Paradox of Civil Society', Journal of Democracy, vol.7, no.3, pp. 38-52.

Goldstein, J. A., \& Hazy, J. K. 2006, Editorial introduction to the special issue: From complexity to leadership and back to complexity, Emergence: Complexity and Organization, vol.8, no.4, pp. v-vi.

Halpern, D. 2005, Social Capital, Polity Press, Cambridge.

Hardy, C., Phillips, N. \& Lawrence, T.B. 2003, 'Resources, knowledge and influence: The organizational effects of interorganizational collaboration', Journal of Management Studies, vol. 40, no. 2, pp.321-347.

Johannisson, B. and Olaison, L. 2007, 'The Moment of truth-Reconstructing entrepreneurship and social capital in the eye of the storm', Review of Social Economy, vol LXV, no, 1, pp.55-78.

Johnston, H. \& Klandermas, B. 1995, “The Cultural Analysis of Social Movements', in H. Johnston \& B. Klandermas, (Eds) Social Movements and Culture, University of Minnesota Press, Minneapolis, pp. 3-24. 
Khagram, S., Riker, J. \& Sikkink, K. 2002, 'From Santiago to Seattle: Transnational Advocacy Groups Restructuring World Politics’, in S. Khagram, J. Riker \& K. Sikkink (Eds) Restructuring World Politics: Transnational Social Movements, Networks and Norms, University of Minnesota Press, Minneapolis.

Langman, L. \& Morris, D. 2002, 'Internetworked Social Movements: The Promises and Prospects for Global Justice’, Proceedings from the International Sociological Association, Brisbane.

Lichtenstein, B. B, Uhl-Bien, M., Marion, R., Seers, A., Orton, J. D., \& Schreiber, C. 2006, 'Complexity leadership theory: An interactive perspective on leading in complex adaptive systems', Emergence: Complexity and Organization, vol.8, no.4, pp.2-12.

Melluci, A. 1995, 'The Process of Collective Identity', in H. Johnston and B. Klandermans, (Eds), Social Movements and Culture, UCL Press, London.

Onyx, J. \& Bullen, P. 2000, 'Measuring social capital in five communities', Journal of Applied Behavioral Science, vol.36, no.1, pp. 23-42.

Putnam, R. 1993, Making Democracy Work: Civic Traditions in Modern Italy, Princeton University Press, Princeton, New Jersey.

Putnam, R. 2000, Bowling Alone: The Collapse and Revival of American Community, Simon and Schuster, New York.

Plowman, D., Solansky, S., Beck, T., Baker, L, Kulkarni, M. \& Travis, D. 2007, 'The role of leadership in emergent self-organization', The Leadership Quarterly, vol.18, pp.341356.

Rogers, M. \& Ryan, R. 2001, 'The triple bottom line for sustainable community development', Local Environment, vol.6, no. 3, pp. 279-289.

Schuller, T. 2001, 'The complimentary roles of human and social capital', Canadian Journal of Policy Research, vol. 2, no. 1, pp. 18-24.

Scott, A. 1990, Ideology and the New Social Movements, Unwin Hyman, Sydney.

Seligman, A.B. 1992, The Idea of Civil Society, Princeton University Press, Princeton New Jersey.

Surie, G. and Hazy, J.K. 2006, 'Generative leadership: Nurturing innovation in complex systems’, in J. K. Hazy, J. A. Goldstein \& B. B. Lichtenstein (eds) Complex Systems Leadership Theory: New Perspectives from Complexity Science on Social and Organizational Effectiveness, ISCE Publishing, Mansfield, MA., pp. 349-366.

Uhl-Bien, M., Marion, R. \& McKelvey, B. 2007, 'Complexity leadership theory: shifting leadership from the industrial age to the knowledge era', The Leadership Quarterly, vol.18, pp.298-318.

Woolcock M. \& Narayan, D. 2001, 'Implications for development theory, research and policy’, World Bank Research Observer, vol. 15, pp. 225-249 